\title{
Comparative Analysis of Kidney Stone Composition in Patients from Ghana and South Africa: Case Study of Kidney Stones from Accra and Cape Town
}

\author{
Evans A. Akpakli ${ }^{1}$, Lisa Kaestner ${ }^{2}$, John Lazarus ${ }^{2}$, Kwame S. Norvixoxo ${ }^{3}$ \\ ${ }^{1}$ Department of Surgery, Korle-Bu Teaching Hospital, Accra, Ghana \\ ${ }^{2}$ School of Medicine, University of Cape Town, Cape Town, South Africa \\ ${ }^{3}$ Faculty of Global Challenges, African Leadership University, Kigali, Rwanda \\ Email: aaevansus25@gmail.com
}

How to cite this paper: Akpakli, E.A., Kaestner, L., Lazarus, J. and Norvixoxo, K.S. (2021) Comparative Analysis of Kidney Stone Composition in Patients from Ghana and South Africa: Case Study of Kidney Stones from Accra and Cape Town. Open Journal of Urology, 11, 53-72.

https://doi.org/10.4236/oju.2021.113007

Received: January 20, 2021

Accepted: March 9, 2021

Published: March 12, 2021

Copyright ( 2021 by author(s) and Scientific Research Publishing Inc. This work is licensed under the Creative Commons Attribution International License (CC BY 4.0).

http://creativecommons.org/licenses/by/4.0/

\begin{abstract}
Background: Kidney stone disease, also termed nephrolithiasis is associated with significant morbidities such as severe colicky flank pain, haematuria, urinary tract infection and kidney failure. Kidney stone disease was perceived as uncommon in developing countries; however, the global prevalence has been rising over the past two decades due to lifestyle changes. There is very limited literature on kidney stone composition in Africa, including Ghana and South Africa. It was based on this evidence that this study was undertaken. Aim: The primary aim of this study was to describe and compare the composition of kidney stone in patients receiving treatment at the Korle- $\mathrm{Bu}$ Teaching Hospital (KBTH), Accra (Ghana) and Groote Schuur Hospital (GSH), Cape Town (South Africa). Methods: The study was a retrospective folder review of patients treated for nephrolithiasis at the Korle-Bu Teaching Hospital in Accra (Ghana) and Groote Schuur Hospital in Cape Town (South Africa). Patients who were treated for kidney stone disease between $1^{\text {st }}$ June 2016 and $31^{\text {st }}$ May 2018 were recruited, and their folder numbers were retrieved from theatre logbooks. A total of hundred and sixty-three $(n=163)$ folders ( $\mathrm{n}=30 \mathrm{KBTH} ; \mathrm{n}=133 \mathrm{GSH}$ ) were subsequently retrieved from the two facilities' records department. Demographic data and kidney stone analysis results were analyzed using the $R$ statistical software. Results: The age of KBTH patients ranged from 24 to 75 years and age of 45 years, while that of GSH ranged 19 to 77 years and median age 48 years respectively. Males were the majority stone formers for both hospitals [56.7\% KBTH; 59.4\% GSH]. There was no statistical difference in gender $(p=0.9447)$ and age $(p=0.2612)$
\end{abstract}


between the two groups. Calcium oxalate (86.7\%) and uric acid $(90.0 \%)$ were the commonest components of the kidney stones analyzed from the KBTH. Calcium oxalate $(66.2 \%)$ and carbonate apatite $(40.6 \%)$ were the most common components stones from GSH. Brushite (3.0\%), cystine (3.8\%) and struvite (19.6\%) stones were only found in GSH patients. All kidney stones from the KBTH were mixed stones. Pure kidney stones were only found among the GSH dataset constituting $48.9 \%$, also female patients from GSH formed more mixed stones than their male counterparts ( $\mathrm{M}: \mathrm{F}=40.5 \%: 66.67 \%)$ and infection kidney stones were also predominantly found among female patients. Conclusion: The findings indicate that the two facilities' participants are not different in terms of gender and age. However, the composition of stones was found to be different between participants from both hospitals. This suggests that kidney stone composition may be influenced by patients' geographical location and or cultural background.

\section{Keywords}

Kidney Stones, Comparative Analysis, Korle-Bu, Groote Schuur

\section{Introduction}

Stone disease of the urinary tract, also termed urolithiasis, is a debilitating, chronic condition, which has affected people (perhaps) since antiquity. It results in great morbidity like severe colicky flank pain; infection and loss of kidney function may occur when the kidney is obstructed by a stone. It may result in loss of working hours and productivity due to repeated patient visits to the emergency unit or urologist, especially during those acute episodes requiring admission and intervention [1].

Kidney stones have been shown to be associated with other chronic diseases like coronary artery disease, hypertension and chronic kidney disease [2]-[7]. This had led to other investigators referring to kidney stone disease as a metabolic disorder beyond the obstructive symptoms caused by these stones.

Kidney stone analysis is essential in assessing stone patients, not only in determining stone composition, but also in providing a guide as to metabolic anomalies that might be involved in stone formation [8] [9]. The knowledge of stone composition is very important in further investigating and treating patients with kidney stone disease due to the high recurrence of this condition [10].

Kidney stone disease was perceived as uncommon in developing countries until recently [11], but they are now a health concern in many developing nations as it is in developed countries. Presently, there is insufficient data in the current literature on the incidence and prevalence of kidney stone disease in Africa and other developing countries [12]. The prevalence of kidney stones has been rising globally over the past two decades due to dietary and lifestyle 
changes [11] [13] [14]. Although studies have reported a low incidence of kidney stone disease in people of African descent compared with, for example, Caucasians, there is also the paucity of information regarding kidney stones and stone composition among Africans [15] [16].

Evidently, stone disease incidence varies with race, ethnicity, occupation, geographic location, climate and diet [1]. These factors and variations in cultural practices and diet also affect the chemical composition of kidney stones. For example, people from South-East Asia consume betel leaves, nuts and calcium hydroxide paste which have been associated with hypercalciuria and hypocitraturia. Individuals from Northern India lack intestinal Oxalobacter formigenes; hence they are unable to metabolize dietary oxalate which causes absorptive hyperoxaluria [1] [17].

Anecdotal evidence shows that physicians manage numerous cases of upper urinary tract stones in clinics across Africa. However, at present, no published study has compared the stone composition between two different African countries. On premise, this study was conducted to determine the composition of kidney stones in our sample (of patients from Korle-Bu Teaching Hospital and Groote Schuur Hospital) and compare the results of these two countries. The populace in Ghana is mainly of African descent, while South Africa includes people of African, European, Asian ancestry and Coloured people. This multi-race scenario in South Africa also presents an opportunity to understand stone composition beyond just a single race and if possible, identify the significance of stone composition and its impact on the nature of kidney stone disease in Africa.

\section{Methods}

This retrospective study involved patients' folder review from $1^{\text {st }}$ June 2016 to $31^{\text {st }}$ May 2018 at the Korle-Bu Teaching Hospital (Accra-Ghana) and Groote Schuur Hospital (Cape Town, South Africa). The study is purely a descriptive study of kidney stone composition of patients who were treated for kidney stone disease in the two hospitals over the study period. Patients with kidney stone disease who were treated at the Urology units of Korle-Bu Teaching hospital (KBTH) and Groote Schuur Hospital (GSH) over the study period and had their stones analyzed were included in this study. The study recruited consecutive patients who were treated for stone disease in the two hospitals.

Ethical approval had been sought and approved from the Surgical Divisional research committee of Groote Schuur and the Human Research Ethics Committee (HREC) of both institutions. Patients who had radiological images (X-ray and CT scan) confirmation of kidney stones and were surgically treated, either by minimally invasive (URS, PCNL, Laparoscopy) or open surgery were used for this study. Theatre logbooks between $1^{\text {st }}$ June 2016 and $31^{\text {st }}$ May 2018 were reviewed for folder numbers of patients who had stone surgeries. These were used to source names from HREC approved urology database of the two hospitals and variable data obtained. Stones collected from patients during surgical procedures 
were labelled and sent to the laboratory for analysis. Two laboratories (i.e. MDS Lancet and Pathcare laboratories) were involved in the analysis of stones for this study. MDS lancet was involved in the analysis of stones from KBTH and Pathcare from GSH. Both laboratories used Fourier transform infrared spectrometer (FT-IR) to analyze the stones. MDS lancet used Thermo Scientific, Nicolet iS10 FT-IR spectrometer and Pathcare used Agilent Technologies, Cary 630 FT-IR spectrometer for stone analysis.

There was not a sufficient study population from which a statistics formula-based sample size calculation could be drawn. Thus, we did not calculate a sample size but used the available folder/data of consecutive patients who were treated for kidney stone disease and had their stones analyzed. A total of thirty $(\mathrm{n}=30)$ and one hundred and thirty-three $(\mathrm{n}=133)$ patient folders were obtained from KBTH and GSH respectively. Data on date of surgery and stone analysis, demography (country of origin, age and gender) and kidney stone composition after analysis were collected using a data sheet. The data was coded and captured into Excel spread sheets and then exported into the statistical package $\mathrm{R}$ where it was cleaned and analyzed [18].

Descriptive statistics such as mean, standard deviation, frequencies and percentages were used to summarize the data (e.g. age, gender and country of origin). A student t-test was used to compare differences on age variables between the South African and Ghanaian samples and a p-value of less than 0.05 is considered statistically significant. In cases where the variable count is more than $5 \%$, Chi-Square goodness-of-fit tests of proportions were used to assess for significance (gender variable between KBTH and GSH). The demographic variables, kidney stone type and kidney stone chemical composition as function of demographic indicator was analysed and compared between the Korle- $\mathrm{Bu}$ Teaching Hospital and Groote Schuur Hospital.

\section{Results}

A total of hundred and sixty-three $(\mathrm{n}=163)$ participants $(\mathrm{n}=30 \mathrm{KBTH} ; \mathrm{n}=133$ GSH) were recruited for this study. The age of participants at the KBTH ranged from 24 to 75 years with a median age of 45 years, while the ages of participants at the GSH ranged between 19 to 77 years with a median age of 48 years. Males were the majority stone formers for both hospitals [56.7\% KBTH; 59.4\% GSH] with ratio of $\mathrm{M}: \mathrm{F}=1.3: 1(\mathrm{KBTH})$ and $\mathrm{M}: \mathrm{F}=1.5: 1(\mathrm{GSH})$. However, there was no significant statistical difference in gender $(p=0.9447)$ and age $(p=0.2612)$ between the two groups as shown in Table 1.

Most of the kidney stones from the dataset were composed of multiple chemical components.

Calcium apatite was only prevalent among stones of KBTH patients but was not observed in any of GSH patients. Contrarily, Struvite was only recorded among patients treated in GSH while none of KBTH stones contained struvite. With regards to chemical composition of stones, most of the stones from 
Table 1. Demographic characteristics of kidney stone patients treated at KBTH (Accra, Ghana) and GSH (Cape Town, South Africa).

\begin{tabular}{|c|c|c|c|c|c|c|c|c|c|c|}
\hline & \multirow{2}{*}{\multicolumn{2}{|c|}{ Gender }} & \multicolumn{8}{|c|}{ Age } \\
\hline & & & \multirow{2}{*}{ Count } & \multirow{2}{*}{ Min. } & \multicolumn{3}{|c|}{ Quantiles } & \multirow{2}{*}{ Max. } & \multirow{2}{*}{ Mean } & \multirow{2}{*}{$\begin{array}{l}\text { Std. } \\
\text { dev. }\end{array}$} \\
\hline & Female & Male & & & $25 \%$ & $50 \%$ & $75 \%$ & & & \\
\hline $\begin{array}{l}\text { Korle-Bu } \\
\text { Counts }\end{array}$ & 13 & 17 & 30 & 24.00 & 34.00 & 45.00 & 53.75 & 75.00 & 45.13 & 14.35 \\
\hline Proportion (\%) & 43.33 & 56.67 & & & & & & & & \\
\hline $\begin{array}{l}\text { Groote Schuur } \\
\text { Counts }\end{array}$ & 54 & 79 & 133 & 19.00 & 38.00 & 48.00 & 59.00 & 77.00 & 48.44 & 14.54 \\
\hline Proportion (\%) & 40.60 & 59.40 & & & & & & & & \\
\hline \multicolumn{3}{|c|}{ Chi-Squared p-value: 0.9447} & \multicolumn{8}{|c|}{ Student t-test p-value: 0.2612} \\
\hline
\end{tabular}

Korle-Bu patients (90\%) contained uric acid, while only a few (about 20\%) of the stones from Groote Schuur contained the chemical compound. Calcium oxalate (CaOx) formed $86.67 \%$ compared with $66.42 \%$ from Korle-Bu patients and Groote Schuur respectively. Carbonate apatite was more common among GSH kidney stones $40.30 \%$, while only $16.67 \%$ of stones from KBTH contained Carbonate apatite. There was however, no apparent difference between stones from both hospitals with respect to the other kidney stone composition category (10\% and $10.45 \%$ for $\mathrm{KBTH}$ and GSH respectively). Kidney stones such as Brushite (3.0\%), cystine (3.8\%) and struvite (19.6\%) were only found in the stones of participants receiving treatment at the GSH while no patient from KBTH formed such stones as shown in Table 2 and Table 3.

More than $49 \%$ of the kidney stones from GSH patients were made up of only one chemical component (pure stones), none of the stones from Korle-Bu on the other hand were pure stones. The proportion of patients who formed stones made up of 3 chemical components are the same for the two hospitals but one patient from Korle- $\mathrm{Bu}$ formed a stone made up of four chemical components (see Figure 1 and Table 4).

The one component stones from GSH, Calcium oxalate was the most common forming $28.57 \%$ of the analysed stones. The other pure stones from GSH were uric acid (13.53\%), struvite $(5.26 \%)$ and cystine $(1.50 \%)$ which was classified among other categories of stones. The majority of the stones examined from Korle- $\mathrm{Bu}$ patients were Calcium oxalate \& Uric acid combination stones (73.33\%), only a small fraction (5.26\%) of Groote Schuur patients had this type of stone. Carbonate apatite $\&$ uric acid combinations stones (13.33\%) were only observed among Korle-Bu patients. On the other hand, calcium oxalate \& carbonate apatite (25.56\%) and carbonate apatite \& struvite (6.77\%) component stones were only identified among stones from GSH as shown in Table 4.

Kidney stones were also analysed as a function of demographic indicators (i.e. gender and age). In this regard, the age variable was subclassified into two groups of patients (a) 45 or younger $(\leq 45)$ and (b) older than $45(>45)$ at the 
Table 2. Chemical components present in kidney stones (number and proportion) in patients treated at KBTH and GSH.

\begin{tabular}{|c|c|c|c|c|c|c|c|c|c|c|c|}
\hline & & \multicolumn{10}{|c|}{ Kidney Stone Chemical Component } \\
\hline & & 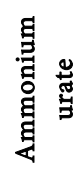 & 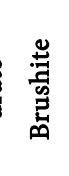 & 祃 䔍 & 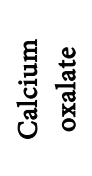 & 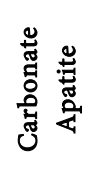 & 葡 & 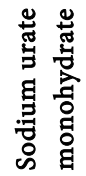 & 营 & 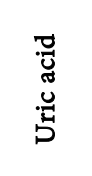 & 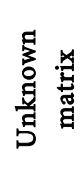 \\
\hline & Count & 1 & 0 & 3 & 26 & 5 & 0 & 1 & 0 & 27 & 1 \\
\hline Korle-Bu & $\begin{array}{c}\text { Proportion } \\
\text { (\%) }\end{array}$ & 3.33 & 0.00 & 10.00 & 86.67 & 16.67 & 0.00 & 3.33 & 0.00 & 90.00 & 3.33 \\
\hline Groote & Count & 5 & 4 & 0 & 88 & 54 & 5 & 0 & 26 & 27 & 0 \\
\hline Schuur & $\begin{array}{c}\text { Proportion } \\
(\%)\end{array}$ & 3.76 & 3.01 & 0.00 & 66.17 & 40.60 & 3.76 & 0.00 & 19.55 & 20.30 & 0.00 \\
\hline
\end{tabular}

Table 3. Compressed kidney stone chemical composition: summary of patients treated at Korle-Bu and Groote Schuur Hospital.

\begin{tabular}{lcccccccc}
\hline & \multicolumn{6}{c}{ Kidney Stone Chemical Compound Constituent } \\
\cline { 3 - 9 } & & $\begin{array}{c}\text { Calcium } \\
\text { Apatite }\end{array}$ & $\begin{array}{c}\text { Calcium } \\
\text { Oxalate }\end{array}$ & $\begin{array}{c}\text { Carbonate } \\
\text { Apatite }\end{array}$ & Struvite & $\begin{array}{c}\text { Uric } \\
\text { Acid }\end{array}$ & Other* \\
\hline \multirow{2}{*}{ Korle-Bu } & Count & 3 & 26 & 5 & 0 & 27 & 3 \\
& Proportion (\%) & 10.00 & 86.67 & 16.67 & 0.00 & 90.00 & 10.00 \\
\multirow{2}{*}{ Groote } & Count & 0 & 88 & 54 & 26 & 27 & 14 \\
Schuur & Proportion (\%) & 0.00 & 66.17 & 40.60 & 19.55 & 20.30 & 10.53 \\
\hline
\end{tabular}

${ }^{*}$ Other: Ammonium urate, Brushite, Cystine, Sodium urate monohydrate and Unknown matrix. NB: This table is similar to Table 2, except for the new class named "Other".

time of examination (Table 5). Regarding demographic characteristics, females tend to have more multi-component (mixed stones) as evident in the three-component class among both Korle-Bu and GSH patients. While all the male stone formers from Korle-Bu had two components stones, more than 23\% of the female stone formers had stones containing at least three chemical components and the only four-component stone observed was formed by a female from KBTH. Also, $60.8 \%$ of the male stone formers from Groote Schuur formed one component (pure) stones. However, more than $66 \%$ of the female stone formers from the same hospital formed stones composed of at least two chemical components (Figure 1).

All Calcium apatite stones, as well as the Other stone category, among Korle-Bu patients are from the females. The Other stone category is also evidently common among female patients at Groote Schuur. Carbonate apatite was absent in all the stones from younger patients of Korle-Bu. However, almost half $48.39 \%$ of stones from younger patients at Groote Schuur had kidney stones containing a carbonate apatite component. The prevalence of carbonate apatite kidney stones was similar for older patients ( $>45$ years) at both hospitals. 
Table 4. Classification of kidney stone as observed among patients treated at KBTH and GSH.

\begin{tabular}{|c|c|c|c|}
\hline \multirow[t]{2}{*}{ Chemical Combinations } & \multirow[t]{2}{*}{ Stone } & \multirow{2}{*}{$\begin{array}{l}\text { Korle-Bu } \\
(n=30)\end{array}$} & \multirow{2}{*}{$\begin{array}{c}\begin{array}{c}\text { Groote } \\
\text { Schuur }\end{array} \\
(n=133)\end{array}$} \\
\hline & & & \\
\hline \multirow{2}{*}{ Calcium oxalate } & Count & 0 & 38 \\
\hline & Proportion (\%) & 0.00 & 28.57 \\
\hline \multirow{2}{*}{ Struvite } & Count & 0 & 7 \\
\hline & Proportion (\%) & 0.00 & 5.26 \\
\hline \multirow{2}{*}{ Uric acid } & Count & 0 & 18 \\
\hline & Proportion (\%) & 0.00 & 13.53 \\
\hline \multirow{2}{*}{ Other ${ }^{*}$} & Count & 0 & 2 \\
\hline & Proportion (\%) & 0.00 & 1.50 \\
\hline \multirow{2}{*}{ Calcium oxalate \& Carbonate apatite } & Count & 0 & 34 \\
\hline & Proportion (\%) & 0.00 & 25.56 \\
\hline \multirow{2}{*}{ Calcium oxalate \& Uric acid } & Count & 22 & 7 \\
\hline & Proportion (\%) & 73.33 & 5.26 \\
\hline \multirow{2}{*}{ Calcium oxalate \& Other* } & Count & 1 & 3 \\
\hline & Proportion (\%) & 3.33 & 2.26 \\
\hline \multirow{2}{*}{ Carbonate apatite \& Struvite } & Count & 0 & 9 \\
\hline & Proportion (\%) & 0.00 & 6.77 \\
\hline \multirow{2}{*}{ Carbonate apatite \& Uric acid } & Count & 4 & 0 \\
\hline & Proportion $(\%)$ & 13.33 & 0.00 \\
\hline \multirow{2}{*}{ Carbonate apatite \& Other } & Count & 0 & 3 \\
\hline & Proportion (\%) & 0.00 & 2.26 \\
\hline \multirow{2}{*}{ Struvite \& Other } & Count & 0 & 4 \\
\hline & Proportion (\%) & 0.00 & 3.01 \\
\hline \multirow{2}{*}{$\begin{array}{l}\text { Calcium apatite \& Calcium oxalate \& } \\
\text { Uric acid }\end{array}$} & Count & 1 & 0 \\
\hline & Proportion (\%) & 3.33 & 0.00 \\
\hline \multirow{2}{*}{ Calcium apatite \& Calcium oxalate \& Other ${ }^{*}$} & Count & 1 & 0 \\
\hline & Proportion (\%) & 3.33 & 0.00 \\
\hline \multirow{2}{*}{$\begin{array}{l}\text { Calcium oxalate \& Carbonate apatite \& } \\
\text { Struvite }\end{array}$} & Count & 0 & 4 \\
\hline & Proportion (\%) & 0.00 & 3.01 \\
\hline \multirow{2}{*}{$\begin{array}{l}\text { Calcium oxalate \& Carbonate apatite \& } \\
\text { Uric acid }\end{array}$} & Count & 0 & 2 \\
\hline & Proportion (\%) & 0.00 & 1.50 \\
\hline \multirow{2}{*}{ Carbonate apatite $\&$ Struvite $\&$ Other } & Count & 0 & 2 \\
\hline & Proportion (\%) & 0.00 & 1.50 \\
\hline \multirow{2}{*}{$\begin{array}{l}\text { Calcium apatite \& Calcium oxalate \& } \\
\text { Carbonate apatite \& Other* }\end{array}$} & Count & 1 & 0 \\
\hline & Proportion (\%) & 3.33 & 0.00 \\
\hline
\end{tabular}

*Other: Ammonium urate, Brushite, Cystine, Sodium urate monohydrate and Unknown matrix. 
Table 5. Number of chemical components per kidney stone of patients treated at KBTH and GSH as a function of age and gender.

\begin{tabular}{|c|c|c|c|c|c|c|c|}
\hline & & & & \multicolumn{4}{|c|}{$\begin{array}{l}\text { Renal Stone Constituent } \\
\text { Chemical Count }\end{array}$} \\
\hline & & & & 1 & 2 & 3 & 4 \\
\hline \multirow{8}{*}{ Korle-Bu } & \multirow{4}{*}{ Age (year) } & $\leq 45$ & Count & 0 & 15 & 1 & 0 \\
\hline & & $\mathrm{n}=16$ & Proportion (\%) & 0.00 & 93.75 & 6.25 & 0.00 \\
\hline & & $>45$ & Count & 0 & 12 & 1 & 1 \\
\hline & & $\mathrm{n}=14$ & Proportion (\%) & 0.00 & 85.71 & 7.14 & 7.14 \\
\hline & \multirow{4}{*}{ Gender } & \multirow{2}{*}{ Female } & Count & 0 & 10 & 2 & 1 \\
\hline & & & Proportion (\%) & 0.00 & 76.92 & 15.38 & 7.69 \\
\hline & & \multirow{2}{*}{ Male } & Count & 0 & 17 & 0 & 0 \\
\hline & & & Proportion (\%) & 0.00 & 100.00 & 0.00 & 0.00 \\
\hline \multirow{8}{*}{$\begin{array}{l}\text { Groote } \\
\text { Schuur }\end{array}$} & \multirow{4}{*}{ Age (year) } & $\leq 45$ & Count & 22 & 36 & 3 & 0 \\
\hline & & $\mathrm{n}=61$ & Proportion (\%) & 36.07 & 59.02 & 4.92 & 0.00 \\
\hline & & $>45$ & Count & 43 & 24 & 5 & 0 \\
\hline & & $\mathrm{n}=72$ & Proportion (\%) & 59.72 & 33.33 & 6.94 & 0.00 \\
\hline & \multirow{4}{*}{ Gender } & \multirow{2}{*}{ Female } & Count & 18 & 29 & 7 & 0 \\
\hline & & & Proportion (\%) & 33.33 & 53.70 & 12.96 & 0.00 \\
\hline & & \multirow{2}{*}{ Male } & Count & 47 & 31 & 1 & 0 \\
\hline & & & Proportion (\%) & 59.49 & 39.24 & 1.27 & 0.00 \\
\hline
\end{tabular}

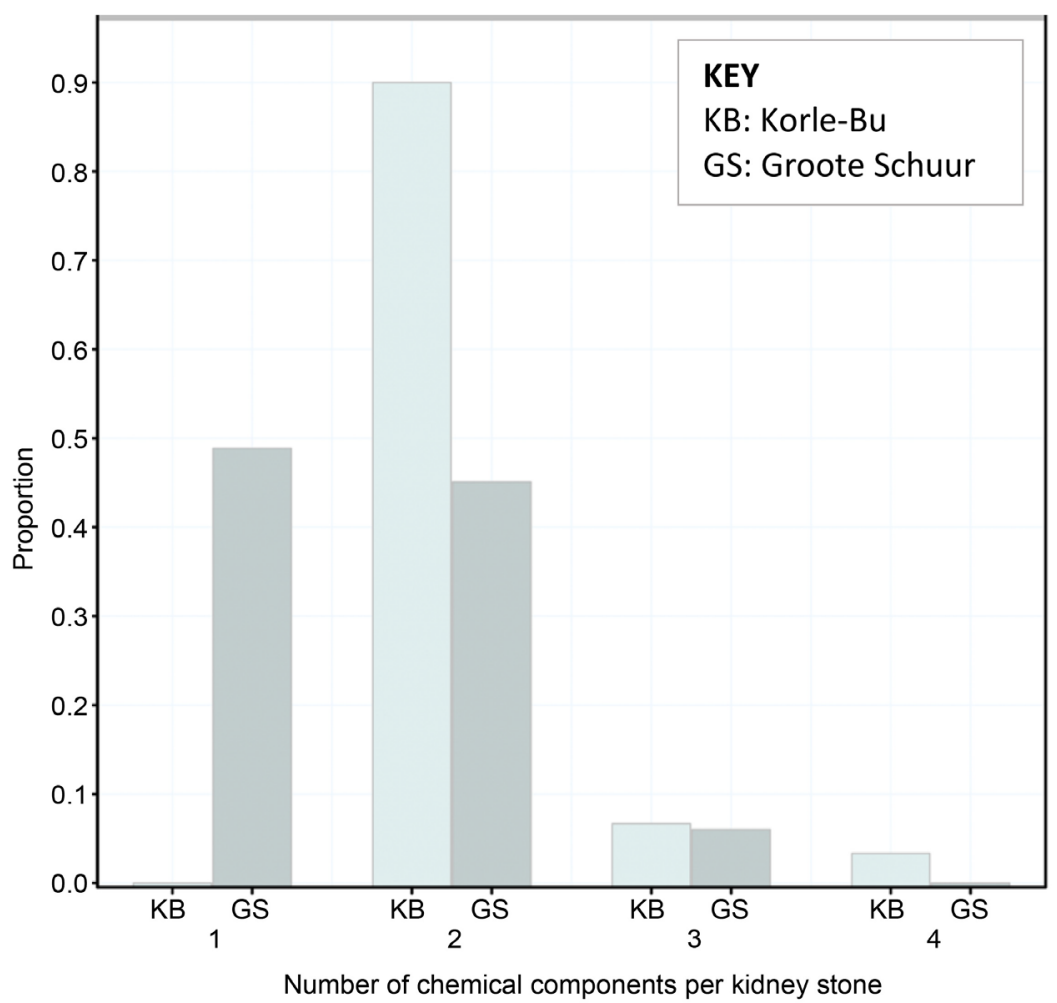

Figure 1. Number of chemical components per kidney stone as a function of the geographic location of patients. 
The participants were diagnosed with kidney stone with abdominopelvic CT scan or X-ray. Blood investigations (full blood count, blood urea, electrolytes and creatinine) and urine studies (urinalysis, culture and sensitivity) were done. Those with evidence of urinary tract infection (UTI) were treated to render the urine sterile before stone extraction. The patients were counselled and consented for surgical stone extraction (retrograde ureterorenoscopy, PCNL, laparoscopy and open surgery). All the participants received prophylactic intravenous antibiotics preoperatively after induction of anaesthesia. Postoperatively the patients were reviewed at 2 weeks, 6 weeks and 12 weeks post-discharge. At first review, abdominopelvic CT scan or X-rays were done to assess for stone clearance. Those found with residual fragments were then scheduled for a second procedure to achieve clearance (stone clearance rate and complications data were not captured, because that did not fall within the scope of this study). To avoid kidney stone recurrence, the patients were offered diet sheet counselling on low-risk stone regimen and liberal oral fluid intake.

\section{Discussion}

Our study demonstrated that the male to female ratio from KBTH was 1.3:1 and that of GSH 1.5:1. This study shows a higher prevalence of kidney stone disease in males than females in both hospitals. However, there is no gender diversity among patients treated for urolithiasis in both hospitals. Various epidemiological studies showed male preponderance [14] [19] [20] which is also confirmed by this study as per the gender characteristics. Some studies have, however, reported a higher M:F ratio: 3.5:1 in Nigeria [11], 2.7:1 in Japan [21] and 3.8:1 in Kenya [22]. In this study, the low male-female ratio is not surprising: Scales et al. [23], in the United States, using in-patient discharges for kidney stone disease from 1997 to 2002 in their study, observed a dramatic rise in female discharges. This demonstrated an increase in the incidence of kidney stone disease in females and therefore, a change in the prevalence of kidney stone disease among men and women from a ratio of 1.7:1 to 1.3:1. This change was attributed to lifestyle changes associated with risk factors such as obesity which is increasing globally due to dietary and behavioural changes [24].

The median age of patients from the Korle-Bu was 45 years (range 24 to 75) and 48 years (range 19 to 77 ) for GSH patients respectively. The age distribution for both hospitals was similar, according to the student t-test $(p=0.2612)$ (Table $1)$. Kidney stone disease can affect all age groups from as young as 6 months to older than 90 years, as Alaya et al. [25] observed in their retrospective study in Tunisia. Even though kidney stone disease affects patients of all age groups, it is evident from epidemiological studies that the peak incidence for this condition occurs between the ages of 20 and 60 years, the most productive age bracket [20], [26] [27] [28]. In this study, the median age of patients is in the $4^{\text {th }}$ decade, with mean ages of $45.13( \pm 14.35 \mathrm{SD})$ and $48.44( \pm 14.54 \mathrm{SD})$ for KBTH and GSH respectively. Studies of kidney stone disease in other African countries observed 
mean ages of 45 years in Nigeria [11], and 43.5 years in Kenya [22] suggesting a similar age distribution of kidney stone patients in other African countries considered in this study.

Calcium oxalate $(\mathrm{CaOx})$ is the most prevalent component of all kidney stones from both hospitals. This is not unexpected as calcium oxalate has been found to be the most predominant component, forming $60 \%$ to $80 \%$, of all kidney stones globally [29] [30] [31]. In an Iceland study conducted by Edvardsson et al. [32], they examined recent trends in the incidence of kidney stone disease in adults over 24 years: $81 \%$ of stones in the study population were CaOx. Ansari et al. [33], reported pure calcium oxalate stones in $93 \%$ of their cohort, of which $80 \%$ were comprised of Calcium oxalate monohydrate (COM) and 20\% Calcium oxalate dihydrate (COD). The high prevalence of $\mathrm{CaOx}$ component of stones in our study is in keeping with a predominance of $\mathrm{CaOx}$ stones globally.

Uric acid (UA) kidney stones account for about $5 \%$ to $10 \%$ of all urinary tract stones. However, the incidence varies globally ranging from $5 \%$ to $40 \%$ depending on the geographic location [34]. It is startling that uric acid was found in $90 \%$ of all kidney stones from Korle-Bu. This result should, however, be interpreted with caution due to the small sample size from Korle-Bu. Uric acid stone formation is attributable to low urinary $\mathrm{pH}(\mathrm{pH}<5.5)$, low urine volume and hyperuricosuria which may be associated with metabolic defect or increased ingestion of purine diet. Korle-Bu Hospital (Ghana) is located in the tropics with high daily temperatures and humidity. These conditions obviously will induce profuse sweating with ensuing dehydration and low urine volumes in the absence of adequate fluid intake. These hot and humid weather conditions in tropical countries favour UA stone formation as described by some researchers [27] [34]. The mechanism by which $\mathrm{UA}$ and $\mathrm{CaOx}$ mixed stones are formed is not absolutely clear; however, the effect of $\mathrm{UA}$ on $\mathrm{CaOx}$ stone formation is due to $\mathrm{UA}$ reducing the solubility of $\mathrm{CaOx}$ in urine; a process referred to as salting-out [34] [35]. A study from Nigeria (a country with similar climatic condition to Ghana) did not identify UA stone among their sample [11]. This might be because Ekeke et al used a qualitative chemical analysis approach to determine stone composition instead of FT-IR spectroscopy. Qualitative chemical analysis of kidney stone has been shown to be beset with many errors in the determining kidney stone composition. Although the proportion of UA stones in the GSH dataset is $20.2 \%$, it evident from (Table 4) that two-thirds of these stones (13.4\%) were of pure uric acid. Pure UA stones are often formed in urine with persistently low $\mathrm{pH}(\mathrm{pH}<5.5)$ which is the significant risk factor for their formation even in the presence of normouricosuria. Pure UA kidney stones are strongly associated with metabolic conditions such as prediabetes, type 2 diabetes and obesity [36] [37]. These individuals have renal tubular insulin resistance and a defect in renal tubular ammonia genesis from glutamine with reduced excretion of ammonium to buffer hydrogen ions. Some researchers such as Torricelli et al. [38], have demonstrated that UA stone formers excrete urine with higher sodium content, lower calcium and lower oxalate contents than 
$\mathrm{CaOx}$ stone formers. The GSH cohort of patients who formed pure UA stones might have conditions associated with persistent acidic urine production, or excrete urine with higher sodium, lower calcium and lower oxalate content.

From Table 2, cystine kidney stones constituted about 3.76\% of stones from the GSH sample; of these, 2 patients formed $100 \%$ cystine stones. None of the stones analyzed from Korle-Bu contained cystine. Cystine stones are relatively rare, constituting about $1 \%$ to $2 \%$ of all kidney stones [39] [40]. Cystine stones are associated with cystinuria; they are usually an autosomal recessive hereditary disorder but sometimes heterozygous gene carriers may be autosomal dominant. The rarity of this condition and the small study population from Korle- $\mathrm{Bu}$, might explain the lack of cystine stones in the KBTH cohort. In Nigeria, another West African country, of the eighty-nine stones analyzed in the study by Ekeke et al. (2018) none were cystine stones. It is plausible that this type of stone might not be found among West African patients. In a kidney stone composition study involving over 1000 stones from northern India, none of the analyzed stones were cystine [33]. This also confirms the rarity of cystine stones. Patients with cystinuria are often predisposed to the development of high blood pressure and chronic kidney disease (CKD); hence these patients should be screened for these diseases and treated accordingly.

As per Table 2, brushite stones were only found among the GSH dataset and constituted $3.01 \%$ of all analyzed stones, but none of the stones from Korle-Bu were brushite. Calcium phosphate stones exist in three forms: Hydroxyapatite, Brushite and Carbonate apatite. Approximately $15 \%$ of all kidney stones are calcium phosphate, of which a quarter are brushite stones. Brushite stones are usually the precursor to the formation of Calcium phosphate stones. In the absence of the conversion of Brushite to Hydroxyapatite, brushite stones are formed [41] [42]. The most important risk factors associated with brushite stone formation are hypercalciuria, elevated urine $\mathrm{pH}$ and higher urine supersaturation with calcium phosphate [41] [42]. Brushite stone formation has been strongly linked to the use of Extracorporeal shock wave lithotripsy (ESWL) to treat kidney stone disease [41]. ESWL is common in Cape Town and widely used as a treatment modality for small kidney stones. In Accra, this treatment option is limited or nonexistent. We are unable to tell whether this might explain the zero brushite stones among patients from Korle-Bu. Another likely explanation for the lack of brushite stones is that at the very extremes of urine $\mathrm{pH}$ (i.e. $\mathrm{pH}<$ 4 or $>8$ ) brushite can spontaneously be converted to Hydroxyapatite stone. Since Hydroxyapatite stones existed among the Korle- $\mathrm{Bu}$ dataset, it is possible that conditions (urine $\mathrm{pH}$ ) might have favoured the conversion of brushite to Hydroxyapatite in the patients from Korle-Bu. Brushite stone formers have a higher risk of developing $\mathrm{CKD}$ than $\mathrm{CaOx}$ patients with prolonged follow up [43]. Therefore, brushite stone formers should be monitored closely for CKD to avert progression to end-stage renal disease (ESRD).

Urate kidney stone (ammonium urate and sodium urate monohydrate) components were only found among Korle-Bu patients. These stones are usually en- 
demic bladder stones. Beukes et al. [44], reported a higher prevalence of urate kidney stones among patients of African descent in their study (from South Africa). On the contrary and quite remarkably, our study did not observe any urate component stones among GSH patients.

Struvite, also known as magnesium ammonium phosphate stones, were only found among the stones from GSH constituting 19.55\% of all analyzed stone samples. Globally, struvite stones constitute $10 \%$ to $15 \%$ of all renal stones. The hallmark of these stones is recurrent urinary tract infections associated with urea splitting organisms. Patients with conditions which predispose them to urinary stasis (urinary tract obstruction, calyceal diverticulum and neurogenic bladder), urinary diversion procedures (continent urinary diversion or ileal conduit), neurologic disorders (spinal injury or pathology), prolonged indwelling urethral catheter and foreign bodies, are prone to developing recurrent UTI and therefore form struvite stones [45]. Over the past decades, the incidence of struvite stones has been observed to be on the decline in developed countries [46]. This had been attributed to the use of effective antibiotics in the treatment of UTIs. Of the 228 renal stones analyzed from the Iceland study, only one of the stones was struvite [32]. Durgawale et al. (2010), however, reported a very high incidence of struvite stones in their series, of which $71.2 \%$ of the analyzed stones contained struvite. This is not surprising since they included stones of the lower urinary tract in their work; stones of the lower urinary tract are often associated with infection. Astoundingly, none of the renal stones analyzed from Korle-Bu were struvite, this might be due to the unregulated antibiotic usage in Ghana this might have kept the urine of stone-predisposed patients from Korle-Bu sterile, hence preventing recurrent UTIs and struvite stone formation. Stone patients from Korle-Bu do not have indwelling double J (DJ) stent for prolonged periods before surgery as in GSH patients. This could also be the reason for the lack of struvite stones from Korle-Bu. Intriguingly, Ansari et al. (2005) reported 180 (20\%) of 1050 observed stones as staghorn calculi in their study of stone composition in northern India. 90\% of these staghorn stones were of oxalate composition (COM and COD) while only $4 \%$ were composed of struvite. This contravenes the evidence that majority of staghorn kidney stones are of struvite composition.

Carbonate apatite stones constitute about $40.60 \%$ of stones from GSH while in Korle- $\mathrm{Bu}$ only $16.67 \%$ of the stone were of carbonate apatite. This is not surprising as carbonate apatite stones are formed as an extension of the cascade of events that lead to struvite stones formation. The majority of carbonate apatite stones are formed in patients with recurrent UTI and persistently high urine $\mathrm{pH}$. Phosphate is insoluble at high urine $\mathrm{pH}$, and under such conditions, it easily precipitates out and combines with calcium and carbonate to form carbonate apatite stones. By extension, carbonate apatite stones are considered infection stones and are often associated with struvite stones.

From Figure 1, stones analyzed from Korle-Bu were heterogeneous or mixed stones made up of at least two or more components. It is therefore not surpris- 
ing that the only 4 component stone came from Korle-Bu. Of the stones from GSH, $48.87 \%$ of the kidney stones were pure stones, and of the mixed stones, the majority of them were of two components (45.11\%). The presence of only mixed kidney stones from Korle-Bu may probably be associated with ethnicity, dietary habits and or climatic conditions prevailing in Ghana. The pure stones in the GSH suggest a possible associated metabolic abnormality in patients who formed such stones.

As illustrated in Table 4, none of the kidney stones analyzed from the two hospitals were of pure carbonate apatite. This is not extraordinary as carbonate apatite seldomly forms pure stones. A carbonated apatite mixed $\mathrm{CaOx}$ stone is often associated with hypercalciuria and relatively alkaline urine in most cases. It may, however, also be related to conditions such as medullary sponge kidney or hyperparathyroidism [9] [47]. Thus, individuals who present with such stones should be screened to exclude the aforementioned disease entities. Carbonate apatite stones formed in combination with struvite are often associated with urea splitting organisms; nonetheless, in the absence of struvite, non-urease producing organisms such as Escherichia coli are usually the causative organism.

Table 5 shows a noticeable difference between gender and stone composition (i.e. pure or mixed). Although all males from the Korle-Bu formed mixed stones made up of two chemical components, females from both hospitals were predisposed to forming mixed stones with complex heterogeneity (two or more component). Struvite stones were only found among the GSH patients and also showed a high prevalence among females as illustrated in Figure 2. This is not unexpected as females are more prone to developing UTI compared with males and hence are more likely to form infection stones [45] [48] [49]. According to Jayaraman et al. (2018), globally, the female to male ratio for struvite stone formers is 2:1. Our study contrarily revealed a much higher ratio of 3.3:1 (F:M) among GSH patients than that observed globally. Notwithstanding this difference of no struvite stones in Korle-Bu cohort of patients, this study also confirmed the predominance of struvite stones in female stone formers. Carbonate apatite stones from this study were predominantly found in female stone formers in both hospitals. Other authors have also reported a greater prevalence of carbonate apatite kidney stones in females than men [49] [50].

The category of stones labelled as Other were mostly stones formed by females from both hospitals. A study from Mayor Clinic Metal Laboratory in the USA reported that over 43,500 of the kidney stones analyzed showed gender variations in stone composition. Females were found to form more apatite (calcium phosphate) and struvite stones while men were prone to forming $\mathrm{CaOx}$ and UA stones [51]. In the same study, Lieske et al. (2014), also observed that females, particularly younger than 40 years, predominantly formed apatite kidney stones. Our study also confirmed that apatite stones were largely found among female stone formers as illustrated in Figure 2. On the contrary, Wathigo et al. (2017) in Kenya and Ansari et al. (2005) in India did not observe any gender disparity of stone composition in their studies. 


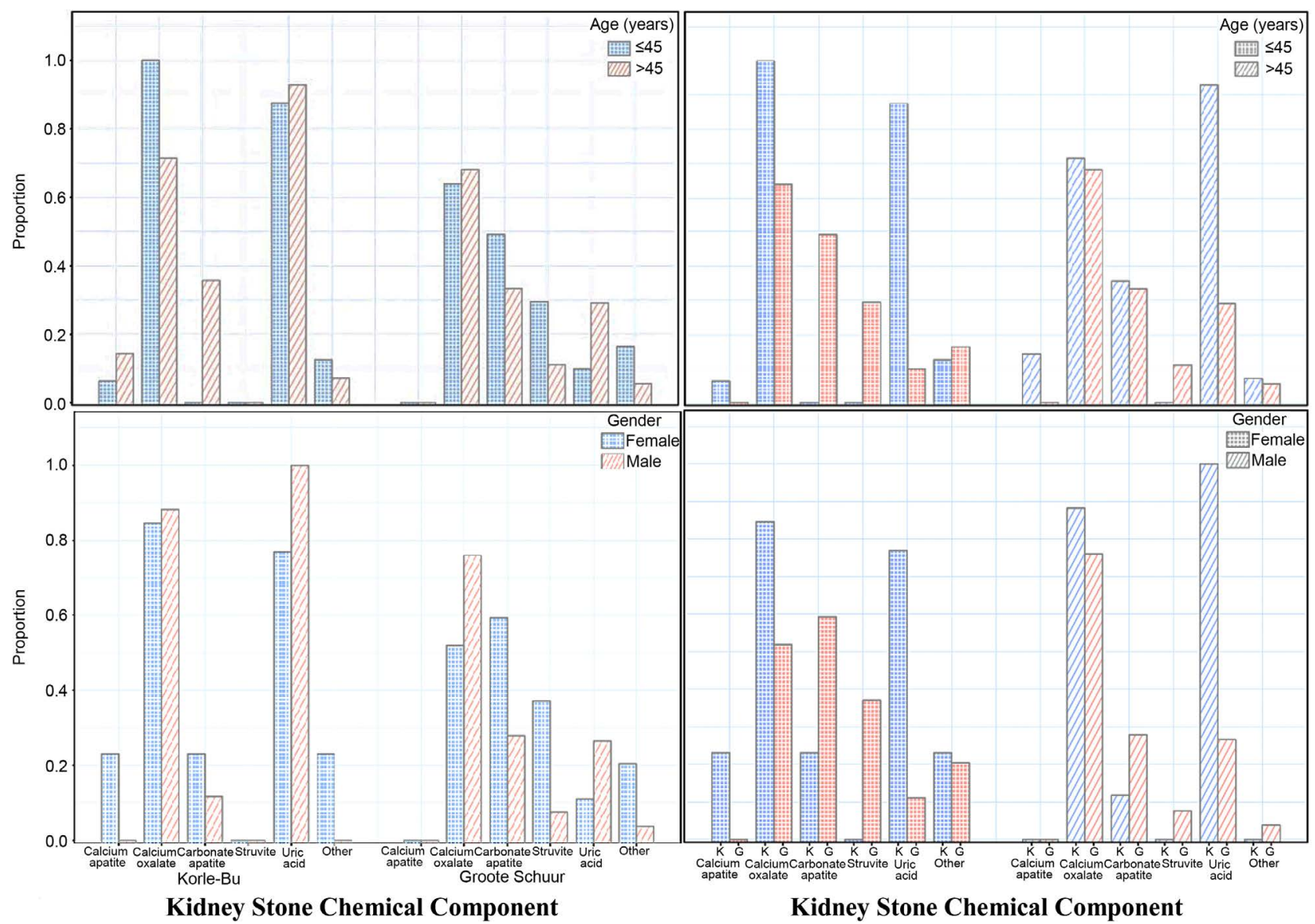

Figure 2. Prevalence of chemical component in the kidney stone of patients treated in $\mathrm{KBTH}(\mathrm{K})$ and $\mathrm{GSH}(\mathrm{G})$ as a function of Age and Gender.

There is evidence that the incidence of kidney stone disease increases with increasing age and also varies with age stratification as observed in some epidemiological studies [24]. Although, our study stratified age of patients into $\leq 45$ years and $>45$ years, we did not study the incidence of stone disease in these age groups. On the whole, the analysis of kidney stone composition among our cohort of patients did not vary between the age groups provided the patients came from the same geographic location. The observation of no difference in stone composition regardless of age has also been reported by other researchers in other countries where kidney stone compositional studies have been conducted [22] [33] [51].

A study conducted in the late 1980s by Beukes et al. [44], on composition and racial distribution of kidney stones from Bloemfontein, South Africa, observed the predominance of $\mathrm{CaOx}$ stones among the racial groups studied. This observation is confirmed by this current study that $\mathrm{CaOx}$ stones are the most common stone type as seen among patients from Ghana (mainly African descent) and South Africa (mixed race) although race was not directly a subject matter in our study. Beukes et al. (1987), observed a higher proportion of struvite and ammonium urate stones (infection stones) among the patients of African des- 
cent in their patient population at the time. Contrary to their observation none of the patients from Ghana had struvite stones. We are unable to confirm in this study whether the infection stones among the South African cohort were more common in a particular race as race stratification was not considered in the study.

The limitation of this study was that: the study did not consider the metabolic abnormalities or the 24-hour urine studies, which are associated with stone formation. If it did, such consideration may have given insight as to why certain stones where formed. This was not an objective of this study but can however be the focus of future studies into comparative analysis of stone composition among different African countries. Furthermore, urinalysis and urine culture were not included in this study though they also affect stone formation and can also be used to assess treatment and follow up on patients with regards to urine $\mathrm{pH}$ and specific gravity.

Lastly, the study used results of stone analysis of patients who were treated in the two hospitals only. Though other institutions also treat patients with stone disease such patients have not been accounted for in this study. Hence the data used for the study might not be as representative of the entire population in Ghana and South Africa. Due to the small data size from Korle-Bu we were unable to stratify age into groups (decades) to determine the incidence of kidney stone disease among different age groups. Notwithstanding the aforementioned limitations, this study set the platform for future collaborative studies between hospitals and laboratories in Africa to determine the incidence of urolithiasis in Ghana and South Africa (and other countries on the continent) on a much broader scale.

\section{Conclusion}

The analyses discussed in this study are based on samples from KBTH and GSH. Both hospitals are open to the public and offer a variety of services to their patients. The study shows a similar gender distribution of kidney stone patients who were treated in Korle-Bu and GSH. There is also no significant difference in age distribution of patients treated for stone disease in both hospitals. Majority of the kidney stones from both countries were made up of $\mathrm{CaOx}$ stones; however, the stones from the Ghanaian cohort were mixed stones of which majority were an admixed calcium oxalate/uric acid composition. Pure kidney stones such as calcium oxalate, uric acid, struvite and cystine were only present among the South African patients. Although some patients from Ghana formed carbonate apatite stones, most stones with this component in this study were predominantly formed by South African patients. Certain kidney stone types, especially brushite, cystine and struvite were only found among the South African population. In contrast, calcium apatite and ammonium urate components stone were found in kidney stones from Ghanaian patients. Female patients predominantly formed carbonate apatite and stones with multiple components (mixed stones) 
from both countries. Notwithstanding the small data especially from Ghana, it is noteworthy to infer from this study that kidney stone composition in Ghana is different from South Africa. Therefore, the composition of kidney stone is recognizably dependent on the demographic region from which the patient originates.

\section{Authors' Contributions}

EAA and JL conceived and formulated this study. All authors made significant inputs in drafting the manuscript, in terms of literature search, data analysis and interpretations, and the paper's final preparation for submission. All authors read and approved the final paper.

\section{Availability of Data and Materials}

The data supporting the conclusions of this manuscript is available in Figshare repository (https://figshare.com/articles/dataset/Data for Paper Comparative Analysis of _kidney_stone_composition_among_patients_from_Ghana_and_South_Africa_ 13519787).

\section{Ethics Approval}

Ethical approval was sought and granted by the human research committee of the faculty of health sciences, UCT (HREC REF:601/2018) and the Korle-Bu Teaching Hospital institutional review Board, Korle-Bu, Accra (KBTH-IRB/00002/2019).

\section{Conflicts of Interest}

All the authors declare no conflict of interest.

\section{References}

[1] López, M. and Hoppe, B. (2010) History, Epidemiology and Regional Diversities of Urolithiasis. Pediatric Nephrology, 25, 49-59. https://doi.org/10.1007/s00467-008-0960-5

[2] Ferraro, P.M., Taylor, E.N., Eisner, B.H., Gambaro, G., Rimm, E.B., Mukamal, K.J., et al. (2013) History of Kidney Stones and the Risk of Coronary Heart Disease. Journal of the American Medical Association, 310, 408-415. https://doi.org/10.1001/jama.2013.8780

[3] Rule, A.D., Roger, V.L., Joseph Melton, L., Bergstralh, E.J., Li, X.J., Peyser, P.A., et al. (2010) Kidney Stones Associate with Increased Risk for Myocardial Infarction. Journal of the American Society of Nephrology, 21, 1641-1644. https://doi.org/10.1681/ASN.2010030253

[4] Rule, A.D., Bergstralh, E.J., Melton, L.J., Li, X., Weaver, A.L. and Lieske, J.C. (2009) Kidney Stones and the Risk for Chronic Kidney Disease. Clinical Journal of the American Society of Nephrology, 4, 804-811. https://doi.org/10.2215/CJN.05811108

[5] Sigurjonsdottir, V.K., Runolfsdottir, H.L., Indridason, O.S., Palsson, R. and Edvardsson, V.O. (2015) Impact of Nephrolithiasis on Kidney Function. BMC Nephrology, 16, Article No. 149. https://doi.org/10.1186/s12882-015-0126-1 
[6] Todd Alexande, R., Hemmelgarn, B.R., Wiebe, N., Bello, A., Morgan, C., Samuel, S., et al. (2012) Kidney Stones and Kidney Function Loss: A Cohort Study. BMJ, 345, e5287. https://doi.org/10.1136/bmj.e5287

[7] Worcester, E.M. and Coe, F.L. (2010) Calcium Kidney Stones. New England Journal of Medicine, 363, 954-963. https://doi.org/10.1056/NEJMcp1001011

[8] Pak, C., Poindexter, J., Adams-Huet, B. and Pearle, M. (2003) Predictive Value of Kidney Stone Composition in the Detection of Metabolic Abnormalities. American Journal of Medicine, 115, 26-32. https://doi.org/10.1016/S0002-9343(03)00201-8

[9] Cloutier, J., Villa, L., Traxer, O. and Daudon, M. (2014) Kidney Stone Analysis: “Give Me Your Stone, I Will Tell You Who You Are!” World Journal of Urology, 33, 157-169. https://doi.org/10.1007/s00345-014-1444-9

[10] Samuell, C.T. and Kasidas, G.P. (1995) Biochemical Investigations in Renal Stone Formers. Annals of Clinical Biochemistry, 32, 112-122.

https://doi.org/10.1177/000456329503200202

[11] Ekeke, O.N. and Okpani, C.P. (2018) Management of Urinary Stone Disease in a Resource Limited Tertiary Hospital. IOSR Journal of Dental and Medical Sciences, 17, 38-45.

[12] Raheem, O.A., Khandwala, Y.S., Sur, R.L., Ghani, K.R., Denstedt, J.D. and Catto, J. (2017) Burden of Urolithiasis: Trends in Prevalence, Treatments, and Costs. European Urology Focus, 3, 18-26. https://doi.org/10.1016/j.euf.2017.04.001

[13] Afshar, K., Jafari, S., Marks, A., Eftekhari, A. and MacNeily, A. (2015) Nonsteroidal Anti-Inflammatory Drugs (NSAIDs) and Non-Opioids for Acute Renal Colic. Cochrane Database of Systematic Reviews, No. 6, Article No. CD006027. https://doi.org/10.1002/14651858.CD006027.pub2

[14] Scales, C.J., Smith, A., Hanley, J. and Saigal, C. (2012) Prevalence of Kidney Stones in the United States Charles. European Urology, 62, 160-165.

https://doi.org/10.1016/j.eururo.2012.03.052

[15] Lewandowski, S. and Rodgers, A.L. (2004) Renal Response to Lithogenic and Anti-Lithogenic Supplement Challenges in a Stone-Free Population Group. Journal of Renal Nutrition, 14, 170-179. https://doi.org/10.1053/j.jrn.2004.04.007

[16] Rodgers, A.L. (2006) The Riddle of Kidney Stone Disease: Lessons from Africa. Urological Research, 34, 92-95. https://doi.org/10.1007/s00240-005-0017-1

[17] Campschroer, L.M.T., Zhu, Y., Duijvesz, D., Grobbee, D.E. and Lock, M.T. (2014) Alpha-Blockers as Medical Expulsive Therapy for Ureteral Stones. Cochrane Database of Systematic Reviews, No. 4, Article No. CD008509. https://doi.org/10.1002/14651858.CD008509.pub2

[18] R Core Team (2017) R: A Language and Environment for Statistical Computing. R Foundation for Statistical Computing, Vienna.

[19] Adamu, B., Alhassan, S.U. and Effa, E.E. (2015) Adjunctive Medical Expulsive Therapy for Kidney and Ureteral Stone Fragments Following Shock Wave Lithotripsy. Cochrane Database of Systematic Reviews, No. 7, Article No. CD009156. https://doi.org/10.1002/14651858.CD009156.pub3

[20] Bensalah, K., Pearle, M. and Lotan, Y. (2008) Cost-Effectiveness of Medical Expulsive Therapy Using Alpha-Blockers for the Treatment of Distal Ureteral Stones. European Urology, 53, 411-419. https://doi.org/10.1016/j.eururo.2007.09.012

[21] Hossain, R.Z., Ogawa, Y., Hokama, S., Morozumi, M. and Hatano, T. (2003) Urolithiasis in Okinawa, Japan: A Relatively High Prevalence of Uric Acid Stones. In- 
ternational Journal of Urology, 10, 411-415.

https://doi.org/10.1046/j.1442-2042.2003.00656.x

[22] Wathigo, F.K., Hayombe, A. and Maina, D. (2017) Urolithiasis Analysis in a Multiethnic Population at a Tertiary Hospital in Nairobi, Kenya. BMC Research Notes, 10, Article No. 158. https://doi.org/10.1186/s13104-017-2474-3

[23] Scales, C.D., Curtis, L.H., Norris, R.D., Patrick Springhart, W., Sur, R.L., Schulman, K.A., et al. (2007) Changing Gender Prevalence of Stone Disease. Journal of Urology, 177, 979-982. https://doi.org/10.1016/j.juro.2006.10.069

[24] Romero, V., Akpinar, H. and Assimos, D.G. (2010) Kidney Stones: A Global Picture of Prevalence, Incidence, and Associated Risk Factors Kidney Stones: A Global Perspective. Reviews in Urology, 12, e86-e96.

[25] Alaya, A., Nouri, A., Belgith, M., Saad, H., Jouini, R. and Fadhel Najjar, M. (2012) Changes in Urinary Stone Composition in the Tunisian Population: A Retrospective Study of 1,301 Cases. Annals of Laboratory Medicine, 32, 177-183.

https://doi.org/10.3343/alm.2012.32.3.177

[26] Phillips, R., Hanchanale, V.S., Myatt, A., Somani, B. and Nabi, G. (2015) Citrate Salts for Preventing and Treating Calcium Containing Kidney Stones in Adults. Cochrane Database of Systematic Reviews, No. 9, Article No. CD010057. https://doi.org/10.1002/14651858.CD010057.pub2

[27] Sofia, N.H., Walter, T.M. and Sanatorium, T. (2016) Prevalence and Risk Factors of Kidney Stone. Global Journal for Research Analysis, 5, 183-187.

[28] Worster, A. and Supapol, B.W. (2012) Fluids and Diuretics for Acute Ureteric Colic. Cochrane Database of Systematic Reviews, No. 2, Article No. CD004926. https://doi.org/10.1002/14651858.CD004926.pub3

[29] Letavernier, E. and Daudon, M. (2018) Vitamin D, Hypercalciuria and Kidney Stones. Nutrients, 10, Article No. 366. https://doi.org/10.3390/nu10030366

[30] Sakhaee, K., Capolongo, G., Maalouf, N.M., Pasch, A., Moe, O.W., Poindexter, J., et al. (2012) Metabolic Syndrome and the Risk of Calcium Stones. Nephrology Dialysis Transplantation, 27, 3201-3209. https://doi.org/10.1093/ndt/gfr703

[31] Tsujihata, M. (2008) Mechanism of Calcium Oxalate Renal Stone Formation and Renal Tubular Cell Injury. International Journal of Urology, 15, 115-120. https://doi.org/10.1111/j.1442-2042.2007.01953.x

[32] Edvardsson, V.O., Indridason, O.S., Haraldsson, G., Kjartansson, O. and Palsson, R. (2013) Temporal Trends in the Incidence of Kidney Stone Disease. Kidney International, 83, 146-152. https://doi.org/10.1038/ki.2012.320

[33] Ansari, M.S., Gupta, N.P., Hemal, A.K., Dogra, P.N., Seth, A., Aron, M., et al. (2005) Spectrum of Stone Composition: Structural Analysis of 1050 Upper Urinary Tract Calculi from Northern India. International Journal of Urology, 12, 12-16. https://doi.org/10.1111/j.1442-2042.2004.00990.x

[34] Abou-Elela, A. (2017) Epidemiology, Pathophysiology, and Management of Uric acid Urolithiasis: A Narrative Review. Journal of Advanced Research, 8, 513-527. https://doi.org/10.1016/j.jare.2017.04.005

[35] Xu, H., Zisman, A.L., Coe, F.L. and Worcester, E.M. (2013) Kidney Stones: An Update on Current Pharmacological Management and Future Directions. Expert Opinion on Pharmacotherapy, 14, 435-447. https://doi.org/10.1517/14656566.2013.775250

[36] Chu, F.Y., Chang, C.-C., Huang, P.-H., Lin, Y.-N., Ku, P.-W., Sun, J.-T., et al. (2017) 
The Association of Uric Acid Calculi with Obesity, Prediabetes, Type 2 Diabetes Mellitus, and Hypertension. BioMed Research International, 2017, Article ID: 7523960. https://doi.org/10.1155/2017/7523960

[37] Sakhaee, K. (2014) Epidemiology and Clinical Pathophysiology of Uric Acid Kidney Stones. Journal of Nephrology, 27, 241-245.

https://doi.org/10.1007/s40620-013-0034-Z

[38] Torricelli, F.C.M., Gebreselassie, S., Calle, J., Monga, M., De, S. and Liu, X. (2014) Can 24-Hour Urine Stone Risk Profiles Predict Urinary Stone Composition? Journal of Endourology, 28, 735-738. https://doi.org/10.1089/end.2013.0769

[39] Chandirika Jayaraman, U. and Gurusamy, A. (2018) Review on Uro-Lithiasis Pathophysiology and Aesculapian Discussion. IOSR Journal of Pharmacy, 8, 30-42.

[40] Shima, M. and Parks, J.H. (2014) Multimodal Treatments of Cystine Stones: An Observational, Retrospective Single-Center Analysis of 14 Cases. Korean Journal of Urology, 55, 515-519. https://doi.org/10.4111/kju.2014.55.8.515

[41] Krambeck, A.E., Handa, S.E., Evan, A.P. and Lingeman, J.E. (2010) Profile of the Brushite Stone Former. Journal of Urology, 184, 1367-1371.

https://doi.org/10.1016/j.juro.2010.05.094

[42] Moreira, D.M., Friedlander, J.I., Hartman, C., Elsamra, S.E., Smith, A.D. and Okeke, Z. (2013) Differences in 24-Hour Urine Composition between Apatite and Brushite Stone Formers. Urology, 82, 768-772. https://doi.org/10.1016/j.urology.2013.04.025

[43] Rivera, M., Jaeger, C., Yelfimov, D. and Krambeck, A.E. (2017) Risk of Chronic Kidney Disease in Brushite Stone Formers Compared With Idiopathic Calcium Oxalate Stone Formers. Urology, 99, 23-26. https://doi.org/10.1016/j.urology.2016.08.041

[44] Beukes, G.J., De Bruiyn, H. and Vermaak, W.J.H. (1987) Effect of Changes in Epidemiological Factors on the Composition and Racial Distribution of Renal Calculi. British Journal of Urology, 60, 387-392. https://doi.org/10.1111/j.1464-410X.1987.tb05000.x

[45] Diri, A. and Diri, B. (2018) Management of Staghorn Renal Stones. Renal Failure, 40, 357-362. https://doi.org/10.1080/0886022X.2018.1459306

[46] Daudon, M., Jungers, P., Bazin, D. and Williams, J.C. (2018) Recurrence Rates of Urinary Calculi According to Stone Composition and Morphology. Urolithiasis, 46, 459-470. https://doi.org/10.1007/s00240-018-1043-0

[47] Daudon, M., Dessombz, A., Frochot, V., Letavernier, E., Haymann, J.-P., Jungers, P., et al. (2016) Comprehensive Morpho-Constitutional Analysis of Urinary Stones Improves Etiological Diagnosis and Therapeutic Strategy of Nephrolithiasis. Comptes Rendus Chimie, 19, 1470-1491. https://doi.org/10.1016/j.crci.2016.05.008

[48] Alelign, T. and Petros, B. (2018) Kidney Stone Disease: An Update on Current Concepts. Advances in Urology, 2018, Article ID: 3068365.

https://doi.org/10.1155/2018/3068365

[49] Ma, R., Luo, X., Li, Q. and Zhong, H. (2018) Systemic Analysis of Urinary Stones from the Northern, Eastern, Central, Southern and Southwest China by a Multi-Center Study. BMC Urology, 18, Article No. 114. https://doi.org/10.1186/s12894-018-0428-2

[50] Carpentier, X., Daudon, M., Traxer, O., Jungers, P., Mazouyes, A., Matzen, G., et al. (2009) Relationships between Carbonation Rate of Carbapatite and Morphologic Characteristics of Calcium Phosphate Stones and Etiology. Urology, 73, 968-975. https://doi.org/10.1016/j.urology.2008.12.049 
[51] Lieske, J.C., Rule, A.D., Krambeck, A.E., Williams, J.C., Bergstralh, E.J., Mehta, R.A., et al. (2014) Stone Composition as a Function of Age and Sex. Clinical Journal of the American Society of Nephrology, 9, 2141-2146.

https://doi.org/10.2215/CJN.05660614 